\title{
MANUFACTURING OF POROUS CERAMIC PREFORMS BASED ON HALLOYSITE NANOTUBES (HNTS)
}

\begin{abstract}
The aim of this study was to determine the influence of manufacturing conditions on the structure and properties of porous halloysite preforms, which during pressure infiltration were soaked with a liquid alloy to obtain a metal matrix composite reinforced by ceramic, and also to find innovative possibilities for the application of mineral nanotubes obtained from halloysite. The method of manufacturing porous ceramic preforms (based on halloysite nanotubes) as semi-finished products that are applicable to modern infiltrated metal matrix composites was shown. The ceramic preforms were manufactured by sintering of halloysite nanotubes (HNT), Natural Nano Company (USA), with the addition of pores and canals forming agent in the form of carbon fibres (Sigrafil C10 M250 UNS SGL Group, the Carbon Company). The resulting porous ceramic skeletons, suggest innovative application capabilities mineral nanotubes obtained from halloysite.
\end{abstract}

Keywords: metal matrix composites (MMC), halloysite nanotubes, porous ceramic preforms

\section{Introduction}

Composites are a group of materials with a very high developmental potential due to the widespread use of modern, lightweight and high strength components [1-3]. On the market of engineering materials, among the widely known and used composite materials, metal matrix composites (MMC) enjoy growing popularity and interest from the industry in recent years. It is noteworthy that the light metal matrix composite materials reinforced by ceramic particles or fibres have excellent properties in comparison with conventional alloys such as lower density, higher strength, increased creep resistance, higher wear and corrosion resistance. MMC are widely used in the aerospace, electronics, automotive and engineering industry, and their production processes are among the fastest growing fields of materials science.

To meet market expectations, in particular in the automotive industry, on elements subjected to high temperature or high wear resistance, it is reasonable to conduct regular activities leading to the development of alternative manufacturing methods of light metal matrix composites. The commonly used reinforcement phases such as $\mathrm{Al}_{2} \mathrm{O}_{3}, \mathrm{SiC}$, carbon or boron fibres, $\mathrm{Al}_{2} \mathrm{O}_{3}$ or $\mathrm{SiC}$ whiskers and particles of $\mathrm{SiC}, \mathrm{Al}_{2} \mathrm{O}_{3}, \mathrm{~B}_{4} \mathrm{C}$ and $\mathrm{TiC}$, as well as carbon nanotubes and intermetallic phases, have many advantages, but are usually costly [1-3]. The search for new materials for reinforcements and alternative manufacturing processes may lead to improvements in the overall performance of metal matrix composites.
The process of manufacturing the MMC by pressure infiltration is the subject of many scientific studies [4,5] because it is characterised by high efficiency and allows neat-net-shape manufacturing. The porous ceramic preform is the semi-finished reinforcing material, where the main feature is the structure of open, interconnected channels, allowing the free flow of molten metal-

Sintered ceramic preforms can be obtained by many methods [6-9]. However, sintering of ceramic powders with the addition of pore-forming agents (e.g. cellulose, polyethylene, carbon fibres) is a flexible method allowing the production of the ceramic preforms. Open, interconnected pore structure enabling penetration of the liquid metal to the whole of preforms volume can be controlled by the selection of the pore-forming addition $[5,10]$. The attractiveness of the infiltrated composites prompted the authors to attempt to develop light metal matrix composites reinforced by porous ceramic preforms manufactured on the base of halloysite nanotubes. HNTs were obtained from hydrogenated aluminium silicate $\mathrm{Al}_{2} \mathrm{Si}_{2} \mathrm{O}_{5}(\mathrm{OH})_{4} \cdot \mathrm{H}_{2} \mathrm{O}$, clay mineral from kaolin group minerals, characterised by low density, high porosity, chemical and thermal stability, the ability to absorb gases, as well as biological compatibility [11]. A review of literature shows that the halloysite nanotubes are widely used in the ceramic industry, in environmental protection as sorbents, coagulants for water treatment, waste immobilizers, as well as in biomedicine as drug carriers, and in the cosmetic industry [11-13]. Halloysite nanotubes have lately become the subject of research consideration as a new type of reinforcement for

\footnotetext{
* INSTITUTE OF ENGINEERING MATERIALS AND BIOMATERIALS, FACULTY OF MECHANICAL ENGINEERING, SILESIAN UNIVERSITY OF TECHNOLOGY, 18A KONARSKIEGO STR, 44-100 GLIWICE, POLAND

\# Corresponding author: kujawa.me@gmail.com
} 
improving the mechanical, thermal and fire-retardant properties of aluminium matrix composites [12-14].

The use of halloysite nanotubes as the reinforcement in the aluminium matrix composites produced by powder metallurgy is a unique invention of the authors [15].

\section{Materials and methodology}

\subsection{Materials}

Porous, ceramic preforms were manufactured by sintering of halloysite nanotubes (HNTs), (Natural Company, USA), with the addition of pores and canals forming agent in the form of carbon fibres (Sigrafil C10 M250 UNS SGL Carbon Group).

Morphology of the halloysite nanotubes was investigated by scanning electron microscope (Fig. 1a). Parameters of particle size analysis by laser diffraction were: quantile $q_{0.1}=0.4 \mu \mathrm{m}$, median $q_{0.5}=2.6 \mu \mathrm{m}$, and quantile $q_{0.9}=11.3 \mu \mathrm{m}$. The analysis of the specific surface area BET by gas adsorption of halloysite powder dried at $100^{\circ} \mathrm{C}$ for 60 minutes in a vacuum and $20 \mathrm{~h}$ in nitrogen was carried out $\left(30.80 \mathrm{~m}^{2} / \mathrm{g}\right.$ and $28.97 \mathrm{~m}^{2} / \mathrm{g}$, respectively). The bulk density, determined as the ratio of the mass of loose powder to the volume of the filled cell in which it is located using a Hall flowmeter (PN-EN ISO 3923-1:2010 E), was $0.17 \mathrm{~g} / \mathrm{cm}^{3}$ and tapped density was $0.25 \mathrm{~g} / \mathrm{cm}^{3}$.

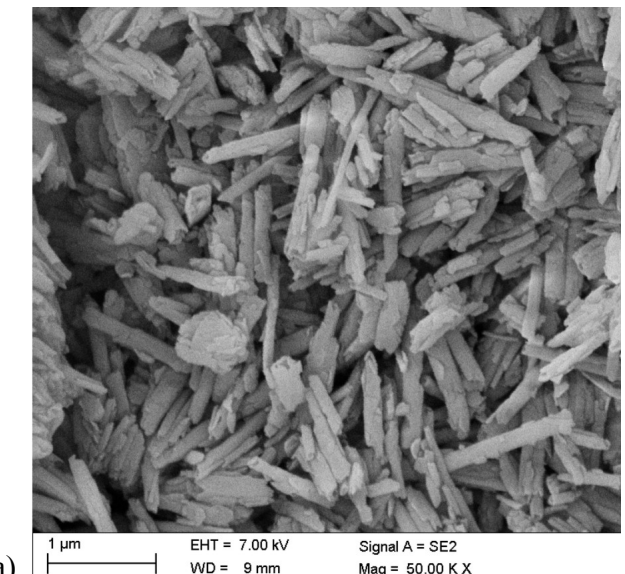

a)

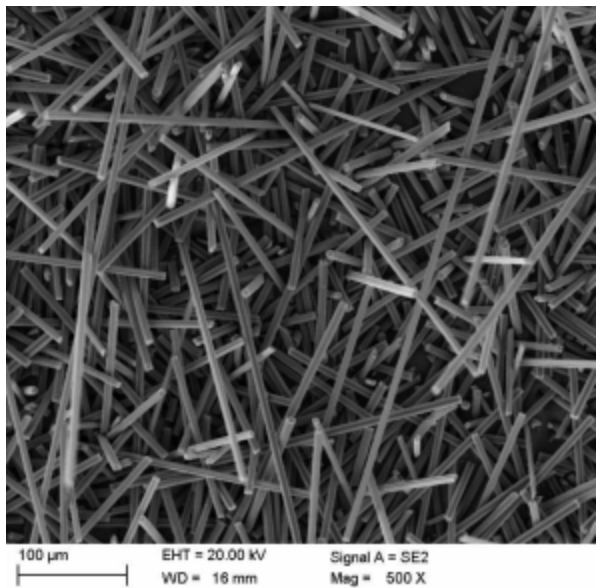

b)

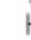
Signal $A=S E 2$
Mag $=500 \mathrm{X}$

Fig. 1. Morphology of halloysite nanotubes (a) and carbon fibres Sigrafil C10 M250 UNS (b)
The results of X-ray qualitative phase analysis of halloysite nanotubes (Fig. 2) indicate peaks characteristic of hydrated halloysite with the chemical formula $\mathrm{Al}_{2} \mathrm{O}_{3} \cdot 2 \mathrm{SiO}_{2} \cdot \mathrm{xH}_{2} \mathrm{O}$.

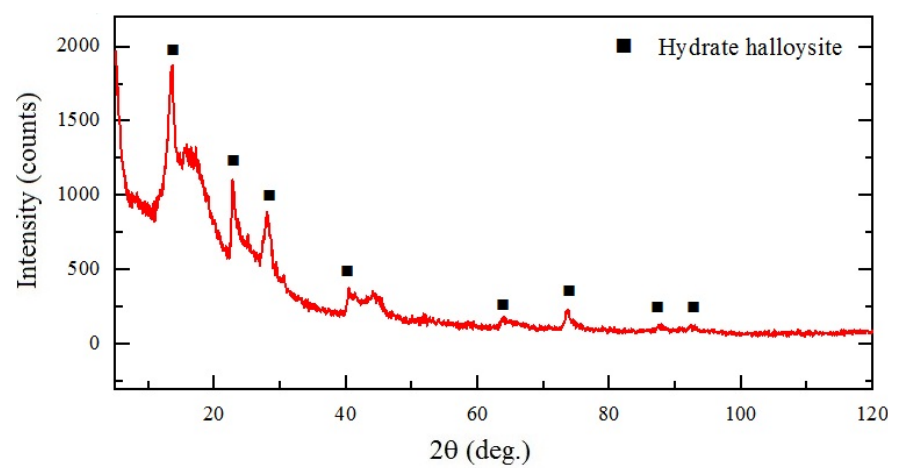

Fig. 2. X-ray diffraction of halloysite nanotubes

Among several commonly used pore and channel - forming agents carbon fibres were selected due to high purity of their degradation. The only product of degradation is $\mathrm{CO}_{2}$, while in the case of cellulose or sawdust, there is a condensed residue, tar, difficult to remove from the walls of the furnace. The morphology of the carbon fibres (Sigrafil C10 M250 UNS) was determined by scanning electron microscopy (Fig. 1b).

\subsection{Technology}

The study includes a set of samples with 50,60 and 70\% of the mass of halloysite nanotubes. Conditions for the preparation of a mixture of powders are shown in Tab 1 . The first stage involved the preparation of moulding powders by weighing mixtures of halloysite nanotubes and carbon fibres. Additionally, a lubricating agent in the form of powder MA7050 (micronized ethylene-bisstearamide-wax) was applied with a mass fraction of $1 \%$ to change the rheological properties of the mixture of powders.

Each of the powder mixtures was subjected to dry milling in a planetary mill Fritsch Pulverisette 6 to break up agglomerates of particles, and to receive uniform distribution of carbon fibres in the entire volume. The milling time was selected on the basis of tapped density of the powder mixtures (Fig. 3), and powder morphology was examined using scanning electron microscopy (Fig. 4).

TABLE 1

Milling process parameters

\begin{tabular}{|c|c|}
\hline \hline \multicolumn{2}{|c|}{ Parameter } \\
\hline Ball - to - powder weight ratio & $10: 1(500 \mathrm{~g}: 50 \mathrm{~g})$ \\
\hline Material of grinding chamber & $\mathrm{ZrO}_{2}$ \\
\hline Capacity of the grinding chamber & $1 \mathrm{dm}^{3}$ \\
\hline Ball diameter & $20 \mathrm{~mm}$ \\
\hline Ball material & $\mathrm{ZrO}_{2}$ \\
\hline Time of milling & $5,15,30,60,120,300 \mathrm{~min}$ \\
\hline Milling speed & $400 \mathrm{rpm}$ \\
\hline Reinforcement contents & $50-70 \mathrm{wt} \%$ \\
\hline
\end{tabular}




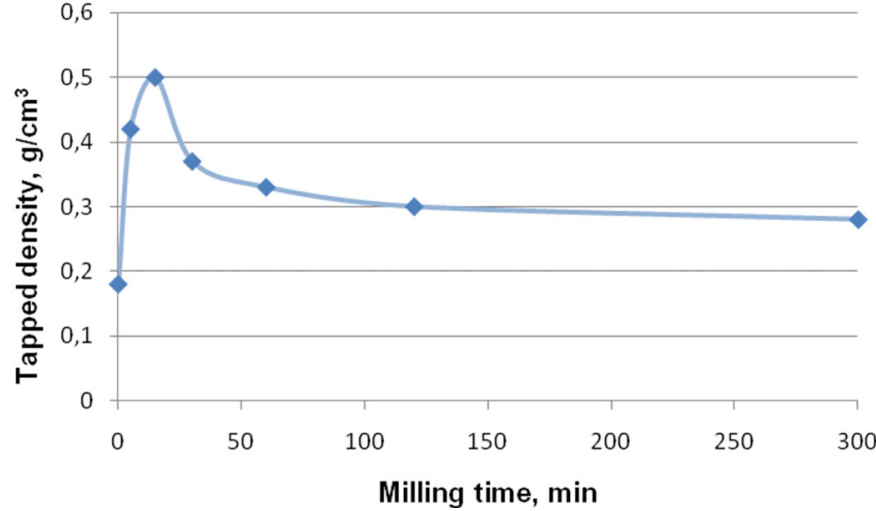

Fig. 3. Dependence of tapped density of the mixture of halloysite nanotubes and carbon fibres (50 $\mathrm{wt} \%$ ) on milling time

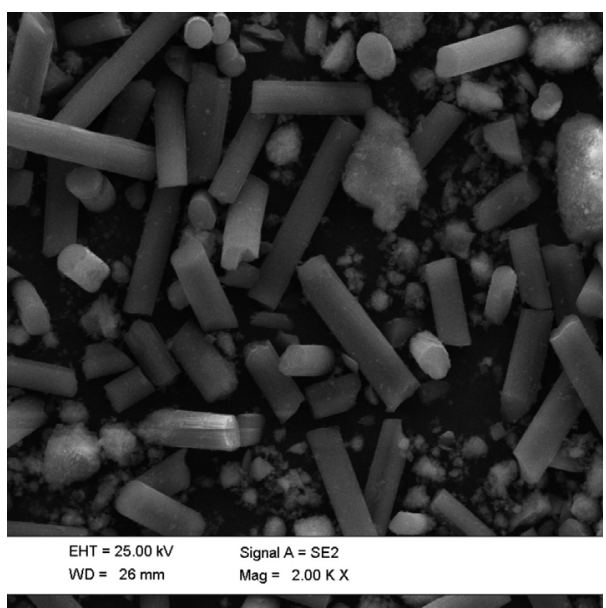

a)

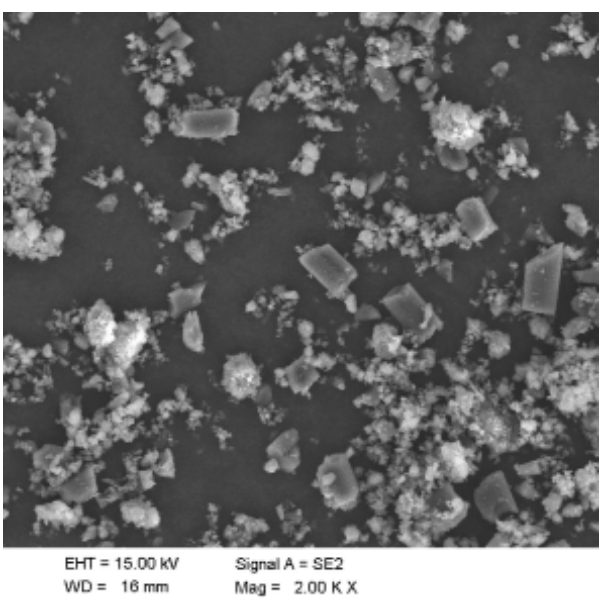

Fig. 4. Morphology of a mixture of halloysite nanotubes and carbon fibres ( $50 \%$ by mass) ball-milled for a) $15, \mathrm{~b}) 120 \mathrm{~min}$

Extension of the milling time resulted in decreased tapped density, therefore powder mixtures after 15 minutes of grinding were selected for further study. The obtained mixtures were subjected to uniaxial pressing (LabEcon 600 Fontijne Grotnes) in a steel mould with the inside diameter of $30 \mathrm{~mm}$. Pressing parameters were as follows: temperature $20^{\circ} \mathrm{C}$, pressure $100 \mathrm{MPa}$, time $15 \mathrm{sec}$. The last step of producing semi-finished products was sintering in a high-temperature furnace (75W PRS of Czy- lok) in the air atmosphere. This process consists of the following procedures: slow heating to a temperature of degradation of carbon fibres; annealing at a temperature of $800^{\circ} \mathrm{C}$, favouring the degradation of the carbon fibres throughout the volume of samples; reheating to the sintering temperature $1500^{\circ} \mathrm{C}$; sintering; cooling with a furnace. The temperature of total thermal degradation is about $700^{\circ} \mathrm{C}$ (Fig. 5), and the sample shows thermal stability up to a temperature of $400^{\circ} \mathrm{C}$. The degradation and sintering temperature was selected experimentally, on the basis of high-temperature microscopy and derivatography preliminary analysis.

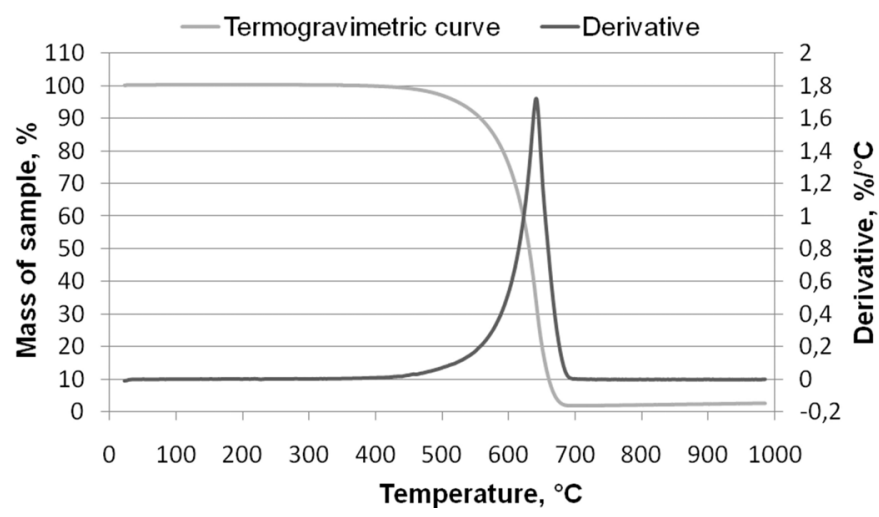

Fig. 5. Thermogravimetric analysis of carbon fibres Sigrafil C10 M250 UNS

The sintering temperature was set at $1500^{\circ} \mathrm{C}$ below transition of cristobalite in amorphous silica.

In the context of the selection of the optimal time between treatments five variants were developed, as shown in Fig. 6. The sintering process of ceramic preforms based on alumina fibres [16] was starting point for optimization of sintering time. The aim of optimization was reducing the time of whole process maintaining complete degradation of carbon fibres, required level of mechanical properties and an open porosity of sintered preform. Reducing of the shrinkage was also important. Finally, the samples sintered in a total time of 9 hours were chosen for further analysis.

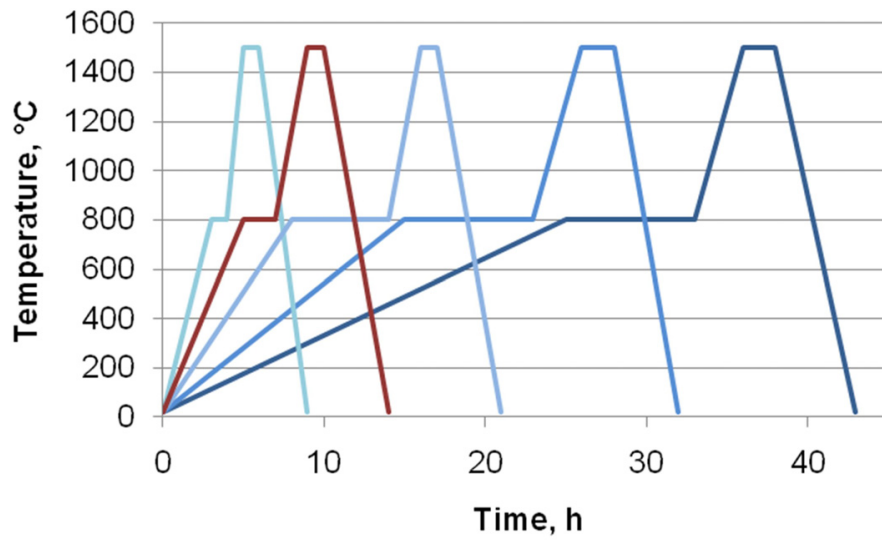

Fig. 6. Sintering process of the mouldings consisting of halloysite nanotubes and carbon fibres. Total time: 1) 43, 2) 32, 3) 21, 4) 14, 5) 9 hours 
Figure 7 shows the mouldings before the sintering process (characteristic black colour comes from carbon fibre) and sintered porous halloysite preforms (white colour confirms the complete degradation of sintered carbon fibres).

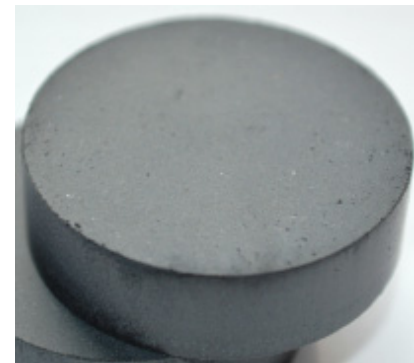

a)

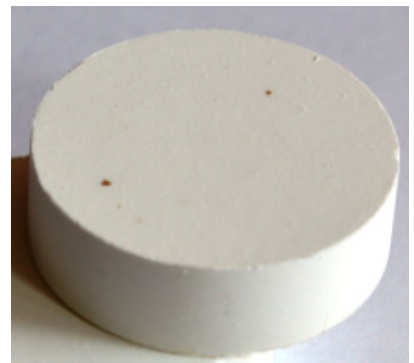

b)
Fig. 7. Green body prepared from a mixture of halloysite nanotubes and carbon fibres (a) and porous ceramic preform after sintering (b)

\subsection{Methodology}

The grain size distribution of halloysite nanotubes was measured by laser diffraction in deionised water at a constant temperature on a Mastersizer 2000 analyser. The morphology observations of powders and preforms were performed using a scanning electron microscope (Zeiss Supra 35). Sintered preforms were measured and weighed to calculate the volume fraction of the ceramic phase. Three-point bending test of the ceramic preforms was performed on a universal testing machine (Zwick Z050).

\section{Results and discussion}

A properly prepared ceramic preform is white, clearly indicating complete degradation of the carbon fibres, and in its structure, open pores and channels occur to allow the free flow of infiltrated metal (Fig. 7b). Structure of open interconnected pores and channels was confirmed using gas pressure infiltration by liquid aluminium alloy (Fig. 8) [17,18]. Figure 9 shows the preform, without stop isothermal at a temperature of $800^{\circ} \mathrm{C}$;

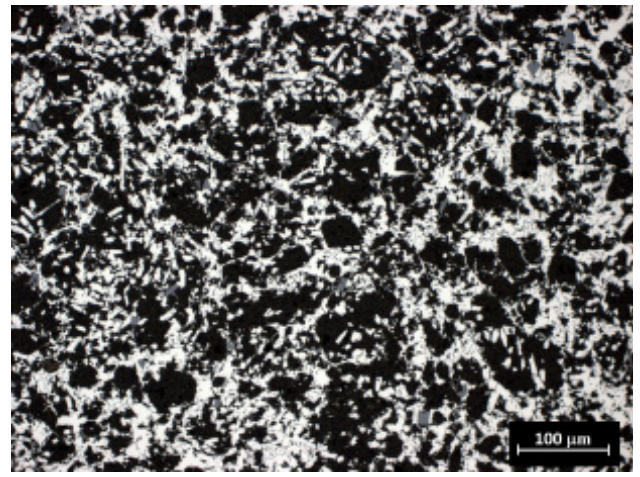

Fig. 8. Structure of the composite material fabricated using gas pressure infiltration of ceramic preform sintered at $1500^{\circ} \mathrm{C}$ thermal degradation of the carbon fibres was not complete. Also, an improperly performed process of preparing the mixtures led to the formation of agglomerates of carbon fibres in the mouldings structure.

a)

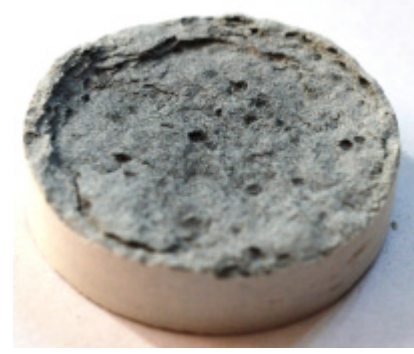

b)

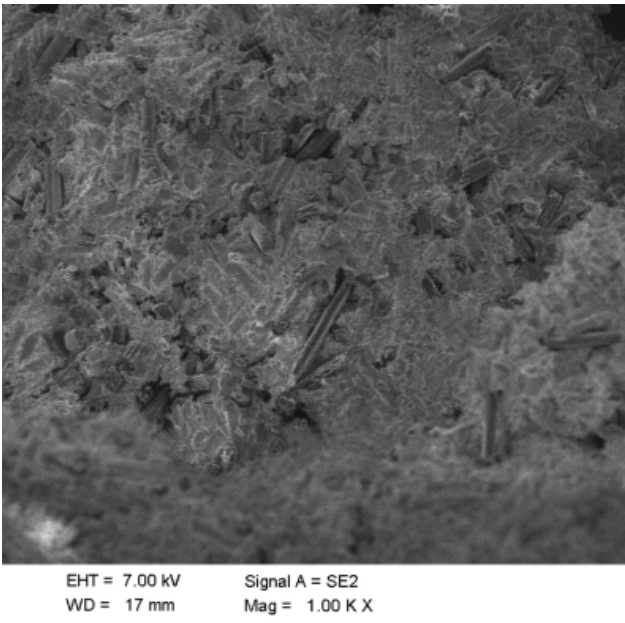

Fig. 9. Porous ceramic preform with partially degraded carbon fibres: a) microphotograph, b) structure

Structures observed in a scanning electron microscope allowed the analysis of surface topography on the fractures of porous preforms. Fractured ceramic preforms received from halloysite nanotubes were porous, as demonstrated in Fig. 10.

Secondary electron imaging enabled identification of two types of pores: regular and relatively larger pores - up to several micrometres - probably caused by degradation of the carbon fibres, and much smaller and irregular pores, occurring particularly around the sintered fine ceramic particles (Fig. 10). The analysed porosity of the ceramic preform is uniform, regardless of the distance from the side edges of the sample. The shape, size, and distribution of the pores are regular throughout the volume of the samples tested. Large, nonporous agglomerates of reinforcing particles were not found, nor - just as important - clusters of pores formed after the degradation of agglomerated carbon fibres. Microstructure SEM analysis of preforms sintered at $1500^{\circ} \mathrm{C}$ also revealed the characteristic, fine mullite whiskers (Fig. 10b).

The results of X-ray qualitative phase analysis of the porous ceramic preforms sintered at a temperature of $1500^{\circ} \mathrm{C}$ (Fig. 11) reveal mullite and cristobalite phases. Due to the structural similarity of cristobalite to quartz the occurrence of other forms of $\mathrm{SiO}_{2}$ cannot be excluded. 

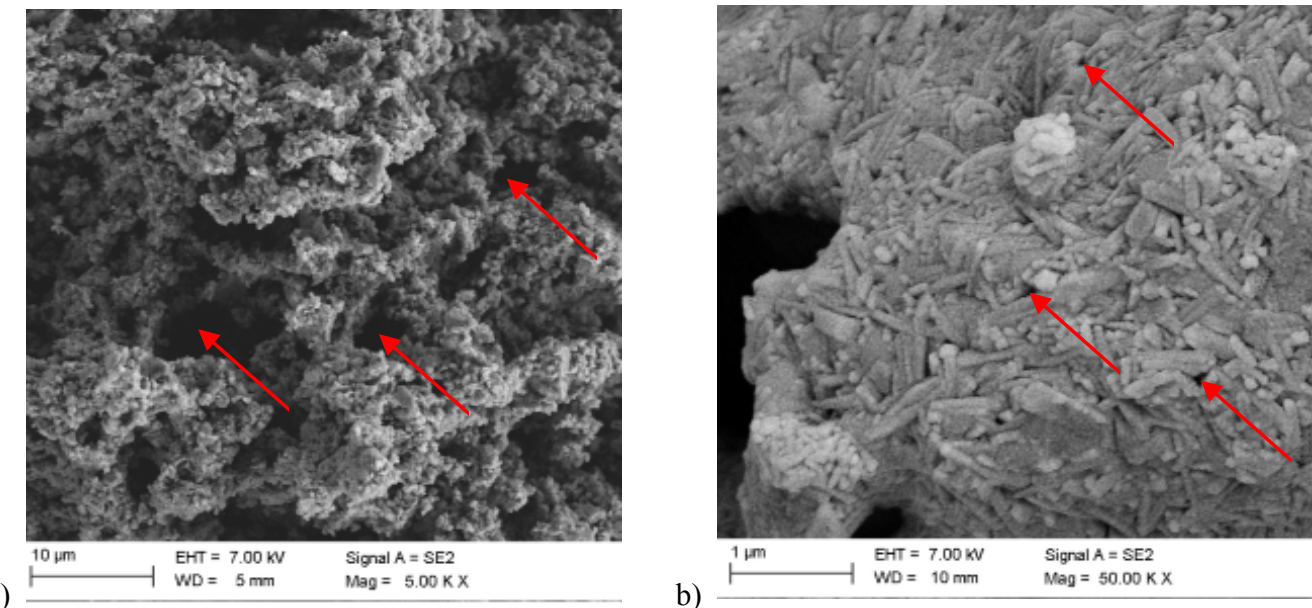

Fig. 10. Microstructure of a ceramic preform based on halloysite nanotubes (a), fine mullite whiskers (b) (arrows - larger pores caused by degradation of the carbon fibres, and smaller and irregular pores, occurring particularly around the sintered fine ceramic particles)

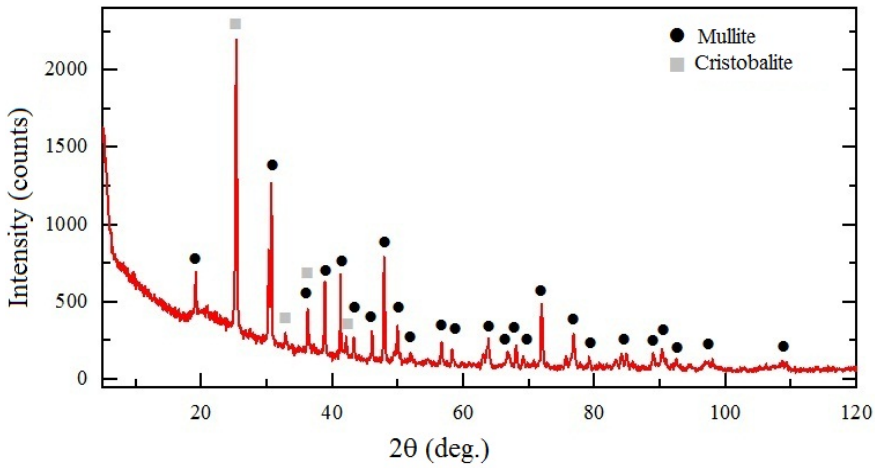

Fig. 11. X-ray diffraction pattern of porous, ceramic preform sintered at $1500^{\circ} \mathrm{C}$

To determine indicative ceramic phase volume fraction in preforms obtained from different powders with different levels of carbon addition, their apparent density and porosity were calculated. The calculations were evaluated on the basis of sintered ceramic preforms geometry and mass measurements. The average apparent densities of porous ceramic preforms sintered from halloysite nanotubes with 30,40 and $50 \%$ volume fraction of carbon fibres are, respectively, $1.4 \mathrm{~g} / \mathrm{cm}^{3}, 1.2 \mathrm{~g} / \mathrm{cm}^{3}, 1.0 \mathrm{~g} / \mathrm{cm}^{3}$. To determine the porosity of the ceramic preforms, it was necessary to measure (based on Archimedes' principle) density of the bulk sample of sintered halloysite nanotubes, which is $3.0 \mathrm{~g} / \mathrm{cm}^{3}$. Based on the above data, it has been calculated that the porosity of the sinter produced involving $70 \%$ halloysite nanotubes is $49 \%$, with the participation of $60 \%$ halloysite nanotubes $-59 \%$ - and with the participation of halloysite nanotubes $50 \%-69 \%$.

Three-point bending test was performed to determine strength of the ceramic preforms of varying porosity. The results in Table 2 show clearly that the bending strength of the ceramic preform increases with the proportion of the ceramic phase. In the group of preforms sintered at $1500^{\circ} \mathrm{C}$, the highest bending strength of 13.2 MPa has been found for the material prepared from a powder mixture containing $70 \%$ halloysite nanotubes.
TABLE 2

The results of the bending strength of the porous ceramic skeletons sintered at $1500^{\circ} \mathrm{C}$

\begin{tabular}{|c|c|c|c|}
\hline \hline $\begin{array}{c}\text { HNTs content, } \\
\text { \% }\end{array}$ & $\begin{array}{c}\text { Pressing } \\
\text { pressure, } \\
\text { MPa }\end{array}$ & $\begin{array}{c}\text { Bending } \\
\text { strength } \mathbf{R}_{\mathbf{g}} \text {, } \\
\text { MPa }\end{array}$ & $\begin{array}{c}\text { Modulus } \\
\text { of bending } \\
\text { strength }\end{array}$ \\
\hline 50 & 100 & 2.9 & 46.0 \\
\hline 60 & 100 & 4.9 & 57.8 \\
\hline 70 & 100 & 13.2 & 48.9 \\
\hline
\end{tabular}

\section{Conclusions}

Halloysite nanotubes, belonging to secondary layered silicates, which at $1500^{\circ} \mathrm{C}$ are transformed into mullite and cristobalite, can be used in the production of sintered porous ceramic preforms. The addition of carbon fibres as a pore forming agent has made it possible to obtain porous ceramic preforms with different structures. The porous ceramic preforms were characterised by the volume percent of the ceramic phase in the range of $46-59 \%$, and porosity of $41-54 \%$. After sintering, ceramic preforms were shrunk by about $20 \%$ in diameter.

The bending strength of the ceramic preforms increases with the percentage of the ceramic phase, and the addition of $70 \%$ HNT causes a threefold increase in bending strength in compare to sample with $50 \%$ HNT.

For the envisaged application, i.e. manufacturing of metal matrix composites, further studies are necessary to arrive at a product with an open porosity of $60-85 \%$, and shrinkage below $5 \%$.

\section{Acknowledgements}

The project was financed by the National Science Centre grant according to the DEC-2011/03/B/ST8/06076 decision number. 


\section{REFERENCES}

[1] K.K. Chawla, Composite materials, Science and Engineering, New York 2012.

[2] A. Hai, C. San Marchi, A. Mortensen, Metal matrix composites in industry: An introduction and a survey, New York 2003.

[3] A.E. Tomiczek, R. Mech, L.A. Dobrzański, Variantion of magnetomechanical properties in giant magnetostrictive composite materials, Polym. Compos. (2015), DOI: 10.1002/pc.23640 (in press).

[4] L. Rongqi, P. Fang, G. Junwei, Y. Xiaozhi, L. Shenzhuo, Z. Wenkai, Z. Xiaoling, Pressure infiltration of boron nitride preforms with molten aluminum for low density heat sink materials, J. Mater. Sci-Mater. El. 24, (4), 1175-1180 (2013).

[5] W. Yu, J.K. Yu, Silicon dissolution and interfacial characteristics in $\mathrm{Si} / \mathrm{Al}$ composites fabricated by gas pressure infiltration, Mater. Chem. Phys. 139, (2-3), 783-788 (2013).

[6] Y. Wang, H. Liu, H. Cheng, J. Wang, Densification behavior and microstructure of mullite obtained from diphasic $\mathrm{Al}_{2} \mathrm{O}_{3}-\mathrm{SiO}_{2}$ gels, Ceram. Int. 40, (8), 12789-12796 (2014).

[7] J. Luyten, S. Mullens, J. Cooymans, A.M. De Wilde, I. Thijs, R. Kemps, Different methods to synthesize ceramic foams, J. Eur. Ceram. Soc. 29, (5), 829-832 (2009).

[8] E.C. Hammel, O.L.-R. Ighodaro, O.I. Okoli, Processing and properties of advanced porous ceramics: An application based review, Ceram. Int. 40, (10), 15351-15370 (2014).

[9] B. Tomiczek, M. Kujawa, G. Matula, M. Kremzer, T. Tański, L.A. Dobrzański, Aluminium AlSi12 alloy matrix composites reinforced by mullite porous preforms, Materialwiss. Werkst. 46, (4-5), 368-376 (2015).
[10] A. Mattern, B. Huchler, D. Staudenecker, R. Oberacker, A. Nagel, M.J. Hoffmann, Preparation of interpenetrating ceramic-metal composites, J. Eur. Ceram. Soc. 24, (12), 3399-3408 (2004).

[11] P. Yuana, D. Tanb, F. Annabi-Bergayac, Properties and applications of halloysite nanotubes: recent research advances and future prospects, Appl. Clay. Sci. 112-113, 75-93 (2015).

[12] D. Rawtani, Y.K. Agrawal, Multifarious applications of halloysite nanotubes, a review, Rev. Adv. Mater. Sci. 30, 282-295 (2012).

[13] R. Kamble, M. Ghag, S. Gaikawad, B. Kumar Panda, Halloysite nanotubes and applications, a review, Adv. Sci. Res. 3, (2), 25-29 (2012).

[14] B. Lecouvet, M.Sclavons, S. Bourbigot, C. Bailly, Thermal and flammability properties of polyethersulfone/halloysite nanocomposites prepared by melt compounding, Polym. Degrad. Stabil. 98, (10), 1993-2004 (2013)

[15] B. Tomiczek, M. Pawlyta, M. Adamiak, L.A. Dobrzański, Effect of milling time on crystallite size and microstructure of AA6061 composites fabricated via mechanical alloying, Arch. Metall. Mater. 60, (2), 789-793 (2015).

[16] L.A. Dobrzański, M. Kremzer, K. Gołombek, Structure and Properties of Aluminum Matrix Composites Reinforced by $\mathrm{Al}_{2} \mathrm{O}_{3}$ Particles, Mater. Sci. Forum. 591, 188-192 (2008).

[17] M. Pawlyta, B. Tomiczek, L.A. Dobrzański, M. Kujawa, B. Bierska-Piech, Transmission electron microscopy observations on phase transformations during aluminum/mullite composites formation by gas pressure infiltration, Mater. Charact. 114, 9-17 (2016).

[18] M. Król, P. Snopiński, B. Tomiczek, T. Tański, W. Pakieła, W. Sitek, Structure and properties of the Al alloy in as-cast state and after laser treatment, P. Est. Acad. Sci. 65/2 107-116 (2016). 